\title{
A Research Agenda for Educational Linguistics
}

\section{Citation}

Uccelli,P., \& Snow, C. E. (2008). A research agenda for educational linguistics. In B. Spolsky, \& F. M. Hult (Eds.), The handbook of educational linguistics (pp. 626-642). Malden, MA:Blackwell Publishing.

\section{Published Version}

doi:10.1002/9780470694138.ch44

\section{Permanent link}

http://nrs.harvard.edu/urn-3:HUL.InstRepos:11654981

\section{Terms of Use}

This article was downloaded from Harvard University's DASH repository, and is made available under the terms and conditions applicable to Other Posted Material, as set forth at http:// nrs.harvard.edu/urn-3:HUL.InstRepos:dash.current.terms-of-use\#LAA

\section{Share Your Story}

The Harvard community has made this article openly available.

Please share how this access benefits you. Submit a story.

\section{Accessibility}




\title{
44 A Research Agenda for Educational Linguistics
}

\author{
PAOLA UCCELLI AND \\ CATHERINE SNOW
}

Our task was to respond to the papers in this volume by suggesting what the most pressing research agenda within educational linguistics might be. Given the wealth of evidence and ideas already presented, it may seem superfluous to develop a further agenda for research activity. But consider the representation of knowledge in any domain as a circle, set in a field that represents the unknown. As knowledge accumulates, the circle grows in area. But the circumference of the circle - representing the questions at the boundary between the known and the unknown - also increases in length, such that adding to knowledge inevitably means generating new questions and reaching new touchpoints with the unknown. Thus it seems appropriate to respond to the wealth of insights accumulated in this volume by identifying the new questions and problems revealed.

Furthermore, educational linguistics, like educational research in general, suffers from inadequate resources in the face of pressing need. Under such circumstances, identifying the most promising and the most urgent issues to attend to can help us use resources wisely, thus demonstrating most effectively the value of pursuing work in this area.

Research in educational linguistics shares a number of challenges with its mother field, research in education. Educational research is a somewhat illdefined domain. It encompasses work that has disciplinary bases as disparate as neuroscience and anthropology, economics and developmental psychology, demography and discourse analysis, history and political science. What has traditionally brought these many strands of work together? Unfortunately, all too often very little. Perhaps the studies made reference to educational settings, or were carried out by researchers working in schools of education, or were published in educational journals, or were presented at one of the several, large meetings of educational researchers, such as those sponsored by the American Educational Research Association or by the European Association for Research on Learning and Instruction. In other words, these strands of research cluster sociologically, but do not necessarily share common features or defining characteristics. 
The lack of a shared definition for educational research might account in part for its lackluster reputation. There are two major complaints about educational research: its poor quality, and its limited effectiveness in helping solve the problems of educational practice. The complaints about quality may be inevitable in a field that encompasses disciplines with very different methodological histories and proclivities. Quality is relatively easy to identify and to maintain in a field where the standards of proof are uniform, but if everything from ethnography to psychometrics, from qualitative analysis of interview data to hierarchical linear modeling are accepted methods, the criteria for rigor are inevitably less shared.

Even within the subfield of educational linguistics, the nature of evidence and standards of proof accepted by various members of the field differ greatly; quantitative sociolinguists and language acquisition researchers present data of quite a different sort from that accepted by experimentally inclined psycholinguists or by discourse analysts. While all those methods have the potential of illuminating educational questions in complementary ways, some greater clarity about the relation of methods chosen to the nature of the data available and the questions being asked would at least help educational researchers counter the claim that their enterprise lacks rigor.

A more important and, we argue, more serious charge against educational research is that it has not contributed sufficiently to the improvement of educational practice. Why is this so? One reason is the absence of procedures to ensure that research-based knowledge about effective educational practice can accumulate. Researchers in older, more prestigious, and more 'scientific' fields see their job as contributing to a growing body of knowledge. The entire enterprise moves forward as researchers use prior studies to define what is not known and thus decide where their energies should be focused. Educational research tends all too often not to proceed in a forward direction determined by what we know. Instead, 'knowledge' swings back and forth, dominant understandings replacing rather than building on each other. For example, educators go back and forth from Thorndike to Dewey, from Piaget to Vygotsky, from skills-focused to constructivist notions of learning, from experimental to interpretive methods, from biological to transactional explanations of development. As long as educational researchers are arguing about such basic notions as whether reading requires using information from print or constructing representations of text (when, of course, in fact it requires both), we can hardly hope to be taken very seriously by classroom practitioners.

Furthermore, we argue in this chapter that educational research writ large, and educational linguistics more specifically, would benefit from taking more seriously the implications of being educational. Research should not be characterized as educational simply because it involves school-aged children, or because it is conducted in schools. We argue for the importance of locating the questions that guide educational research in schools. Any teacher formulates in the course of any day dozens of insights and questions about learners and learning, yet teacher knowledge is not taken very seriously by 
researchers. Serious attention to those insights and questions would not only improve the teacher's effectiveness, but might also lead researchers to deeper understanding.

That so many questions of relevance to teachers have been formulated and addressed in the work reported in this volume is heartening. Indeed, much of the work on second and foreign language acquisition (Huhta, Chapter 33, this volume; Pica, Chapter 37, this volume) as well as on computer-assisted language learning (Chapelle, Chapter 41, this volume) constitutes a model of what we advocate: research that is practice-embedded and practice-inspired, thus practice-relevant by design rather than as a result of retro-fitting. In this chapter, we highlight examples of such work and suggest ways in which other subfields of educational linguistics might benefit from more central attention to the questions generated by practice. The work presented in this volume ranges widely, and in its range attests to the vibrancy of the field of educational linguistics. It may be time, though, to narrow the range of what we define as educational linguistics, in order to ensure that the relevance of knowledge about language to the improvement of educational outcomes be maximized.

\section{The Main Streams of Work in Educational Linguistics}

It is worth noting, as a starting place, the major lines of work that comprise educational linguistics. Indeed, the table of contents of Part II of this volume provides a good overview of these lines of work. We would characterize these domains (deviating somewhat from the names provided by the volume editors) as follows:

- using language in classrooms,

- literacy development,

- language learning,

- planning language use in educational settings,

- assessing language knowledge.

Clearly, the role of educational linguistics in each of these domains is somewhat different. In the first three domains, the primary customer for linguistic insight is the classroom teacher, who would benefit from knowing how his/ her own language use facilitates or interferes with student learning, from understanding the linguistic challenges inherent in texts and classroom discourse, from valuing (while also decreasing) the linguistic variability displayed by student language users, from understanding how to shape classroom discourse to promote active engagement, critical thinking, and rapid learning, and from specific techniques to promote language and literacy 
development. In the last two domains, the primary customer is the ministry of education or the local educational authority, responsible for decisions about which language to use in schools, what standards for use of that language to impose, and how to assess whether those standards are being met.

Furthermore, work on educational linguistics will inevitably have varying priorities in different parts of the world. Each region faces unique challenges, and educational researchers need to attend to those challenges with a genuine focus on the specificity of each situation. In some places, for example, issues of educational language planning hardly arise. Yet, whether the focus is on the 781 million illiterate adults in the world (http://portal.unesco.org/education), on the need to prepare students for tertiary education beyond national boundaries and thus often in a second language (http://www.uis.unesco.org/ ev.php?ID=6028_201\&ID2=DO_TOPIC), or on the design of education for either indigenous or immigrant students who do not speak the national language (http://www.cal.org/topics/ell/), certain fundamental questions arise:

1 What should we be teaching our students about language to prepare them for academic success, for professional success, for their broader intellectual challenges in adult life?

2 What do teachers need to know about language in order to be effective in promoting the desired linguistic outcomes with the full range of students in their classes?

3 Once we have identified the desired linguistic outcomes of education and the required teacher knowledge, how do we go about fostering them?

In the sections that follow, we use these three questions both to organize the knowledge accumulated across the various chapters and as a first cut in specifying more precisely the most urgent questions for the future.

\section{What Are the Desired Educational Outcomes?}

What are the desired educational outcomes at each level of schooling, and how can we adapt them to diverse populations without abandoning high standards, yet taking into consideration the range of circumstances under which learning must occur? LoBianco (Chapter 9, this volume) insightfully lists eight overarching goals that display the range of secondary linguistic socializations schools aspire to produce. This enumeration of goals illustrates in great detail the complexity of the multiple tasks involved in socializing students into various modes of communication. The complexity only increases if we take into consideration that these eight discrete goals frequently overlap in the reality of many educational institutions, as language minority issues, multilingualism, disciplinary linguistic knowledge and language-related special needs are often coexisting factors that instruction needs to address. 
Two tensions seem to lie at the core of defining what the educational outcomes should be in various contexts. The first one is the tension between homogeneity and diversification. Defining the 'standard language' to be used at school is challenging as student bodies become increasingly diverse and successful communication outside the classroom often calls for alternative language forms. Indeed, Nekvapil (Chapter 18, this volume) argues that "the standard" should move toward a polycentric nature, formed by mixed home languages, and accessible to all, not only the elites. While this might constitute a controversial claim, it points to a core definitional feature that cannot be overlooked in establishing educational outcomes related to language. The increasing mobility of the world population, generating contact among more languages and more cultures than ever before, raises to prominence the following questions: What is (are) the standard language(s) to be taught at school? What is the best way for students to have access to it (them) in harmonious coexistence with their primary forms of discourse? Recent projects that seek to develop dialect awareness (Wolfram, Schilling-Estes, \& Hazen, 1997; Reaser \& Wolfram, 2005) and strategies to help language minority students recognize and switch to academic English features (LeMoine, 2001) offer initial insights on the integration of language varieties in the classroom (see Reaser \& Adger, Chapter 12, this volume). There is, however, a long road ahead for research that seeks to identify the optimal outcomes and the best instructional strategies for different populations under a variety of conditions.

The second related tension deals with centralization versus local control. North (Chapter 16, this volume) points out that for foreign language teaching a legitimate question is whether learning can be expected to progress in the same order across a variety of contexts. This is a concern that can easily be extrapolated to the discussion of standards for oral and literate school language as well. Should we have common centralized standards at different levels of schooling regardless of students' characteristics, or should we develop different sets of standards taking into account students' linguistic characteristics? As pointed out by Davies (Chapter 34, this volume), recent research has highlighted the need for adapting standards and assessments to the characteristics of certain populations, such as English language learners and students with special needs (Bailey \& Butler, 2004). How to set realistic standards that attempt to close the achievement gap in the most efficient possible way is still a challenging task that deserves further attention. In discussing the Common European Framework for foreign language instruction, North (Chapter 16, this volume) describes it as a metasystem to be used not as a direct implementation tool but as a reference point from which elaboration and adaptation to local circumstances are necessary. As he points out, whether some categories of this model can prove relevant in the context of school language education more broadly defined remains to be seen.

Finally, the "textually mobile world" (Hull \& Hernandez, Chapter 23, this volume), characterized both by rapid shifts in populations and languages and 
by technological innovations occurring with unprecedented speed, requires redefining desired educational outcomes toward greater flexibility, a more global perspective, and the development of critical thinking. Students in school today need to be prepared to face not yet identified social and intellectual demands. While pragmatic orientations are gradually replacing traditional ones, in this attempt to promote more functional goals, we need to consider how explicit and how inclusive educational objectives ought to be. Hull and Hernandez (Chapter 23, this volume) highlight the rapidity of technological changes, inviting us to redefine what literacy means in a digital world. Shin and Kubota (Chapter 15, this volume) ask "how might one envision and practice a more linguistically and culturally responsive education in the postcolonial and globalized schools of today?" To this valid concern for a responsive education, we would add that of a responsible education. Communication skills should promote respectful dialogue, and literacy skills should allow for entry into deep contact with remote ideas, cultures, and people. We believe that an important aspect of language and literacy pedagogy should be to promote understanding and deep knowledge of our globalized and multicultural world by encouraging reading that emphasizes perspectivetaking and by fostering language skills that focus on communication and lead to real dialogue.

\section{What Do Teachers Need to Know about Language?}

The issue of what teachers need to know about language is, of course, a burning and recurrent problem for educational linguists. There is a very long list of 'need to knows', for example:

- understanding the difference between non-standard dialects, second language characteristics, and language disorders (see Reaser \& Adger, Chapter 12, this volume);

- understanding the inevitability of variation in language use, and the identity work such variation accomplishes (Mesthrie, Chapter 6, this volume);

- understanding the characteristics of normal language development, in both first and second language speakers, and how to measure it (Huhta, Chapter 33, this volume);

- understanding how oral language both relates to and differs from written language, and what (meta)linguistic skills children need to be explicitly taught in order to make the transition from oral to literate comprehension;

- understanding what constitute normal developmental errors in spelling and in writing, and which student errors should be responded to with explicit instruction; 
- knowing enough about etymology and morphology to be able to explain the meanings of words and their morphological and etymological neighbors.

This brief list could be greatly extended (see Fillmore \& Snow, 2002; Valdés et al., 2005). Most notably, though, this list primarily reflects declarative knowledge, whereas in fact an additional long list of linguistic knowledge items could be added that fall more in the domain of enacted knowledge, for example:

- knowing what kinds of questions to ask to generate productive classroom discussions;

- using sophisticated vocabulary words frequently in the course of interactions with students;

- understanding what aspects of written text are likely to be confusing to students;

- understanding how to respond to student writing to make it more sophisticated;

- being familiar with many literary and expository texts of potential interest to students.

The difficulties of providing teachers with sufficient declarative knowledge about education are clear; ensuring the availability to them of enactable knowledge is even more challenging (see Snow, Griffin, \& Burns, 2005, for a further discussion of the distinction between declarative and enacted knowledge). Various teacher education programs have tried sending their students to courses in the linguistics department, or hiring in a linguist to teach pre-service teachers about language; such experiments are not notably successful (Burling, 1971, gives a charming account of the difficulties of this model from the linguist's perspective) for many reasons, including of course the multiplying list of competencies teacher certification programs must provide access to.

This array of challenges thus generates the following sorts of research questions: What is the minimal level of linguistic understanding needed by teachers engaged in initial literacy instruction? By teachers working with older students? By teachers whose students include second language learners? When is it most effective and most efficient to provide instruction in educational linguistics to teachers; are these matters better dealt with as part of professional development than as part of preservice programs? And what language skills and domains of linguistic knowledge should be considered as admissions criteria to teacher education programs? What would be the effect of teaching more linguistics in secondary grades on the knowledge and skills of teacher education students? In addition to specifying what teachers need to know, the question arises: How can this knowledge be made accessible and permanent without having folk language theories reemerge and replace educated theories? 


\section{How Do We Foster the Desired Linguistic Outcomes for Students and Teachers?}

Fostering the desired linguistic outcomes - both declarative knowledge and enactable skills - among students and teachers requires both learning more about the processes of language and literacy acquisition, and figuring out how better to implement what we know. We discuss these challenges under four headings: in the first section we discuss a new way of doing educational research including educational linguistics, and in the remaining sections we present some specific domains where such research could be focused.

\section{Enriching research-practice relationships}

A theme alluded to in many chapters is the one already noted above: the value of embedding research in the realities of practice. It is worth noting that the articles in Part III: Research-Practice Relationships in this volume focus mostly on second language acquisition. The predominance of work on second language learning and language teaching over that on first language and contentarea learning reflects the current reality in the field of educational linguistics, and derives from the obvious role of language in second/foreign language teaching. We argue, though, that more attention needs to be devoted to the role of oral language skills in the accomplishment of literacy and of academic skills, a domain where the linguistic factors may be less obvious, but are no less important.

If, as several of the chapters in this volume agree, researcher-practitioner collaborations are productive in improving the quality both of research and of practice, then the burning questions become: How do we build researcherpractitioner collaborations so that they are feasible, robust, and mutually informative? How do we get teachers - in particular content-area teachers interested in, aware of, and reflective about language in their daily practices? Attempts to create educational settings that function like teaching hospitals, where clinicians and researchers work side by side, have been launched. Professional development schools (see http://www.ncate.org/public/ pdswhat.asp?ch=133) are one example. The Strategic Educational Research Partnership (SERP; Donovan, Wigdor, \& Snow, 2003) has established 'field sites' in collaborating school districts in which practitioners nominate issues of concern and co-construct solutions with researchers who see themselves as engineers constructing tools to solve problems of practice. The need for educational linguists to work within such settings is obvious, since many of the problems of practice being nominated are deeply language related. For example, in the SERP field site established in the Boston Public Schools, the burning issue of concern is middle school students' reading comprehension, in particular their vocabulary knowledge, and their capacity to understand the discourse of content-area texts. 
If research is truly to be informed by practitioner knowledge, then systematic ways must exist for researchers to learn what practitioners think and what they want to know. SERP, for example, has launched a pilot survey to collect information about middle school teachers' literacy-related beliefs and questions (www.serpinstitute.org); some data from a practitioners' survey of unanswered questions about Computer Assisted Language Learning is available at http://www.stanford.edu/ efs/callsurvey/index.html.

In addition to formulating questions based on practitioners' concerns, researchers need to think about how to design data collection and analyses that are beneficial to all participants involved. Practice-oriented research studies on second or foreign language teaching offer valuable examples. As described by Pica (Chapter 37, this volume), the field of second language acquisition has recently moved toward closer teacher-researcher collaborations that illustrate the type of practice-inspired and practice-relevant approach we advocate here. The strategies implemented, and the lessons learned in these studies, are relevant beyond the field of SLA and can inform research on the language of schooling and on literacy more broadly. In discussing instructional techniques, Pica proposes four basic principles that seem relevant as guidelines for practicerelevant research, independent of the specific curricular content selected. Following her basic principles, we think effective collaborations will be those that focus on authentic tasks, the least complex implementation possible, areas where students need additional targeted instruction, and noticeably successful outcomes. Successful partnerships would result in a bi-directional relationship, in which research informs practice, and theories are reformulated and refined based on their encounters with real-life challenges. Given that recent research on second language acquisition attests to the feasibility and fruitfulness of this reciprocal influence (see Pica, Chapter 37, this volume), other subfields of educational linguistics can use these principles as starting points to forge theory and practice relationships. In this collaboration, policy making needs to be involved for successful results. Connecting the standards used across instruction, assessment, and policy making is a key requirement for an efficiently integrated system that offers feedback to its different components. As discussed by King and Benson (Chapter 24, this volume), for instance, not only are various definitions of literacy used in different parts of the world, but these definitions tend to be narrow and simplistic in some policy circles. An elaboration of the commitment to practice-embedded research is the pragmatic orientation embraced by Davies' discussion (Chapter 34, this volume) of the design of the PISA, with its focus on measuring knowledge required in everyday tasks beyond the school setting. Davies also proposes studies of the impact of language assessment on the quality of instruction and on the quality of the standards proposed. This approach emphasizes the degree to which good language teaching exploits information from assessment to inform better instruction and set more clearly defined educational objectives.

The two areas into which Hudson (Chapter 5, this volume) divides theory are of great relevance to thinking about how researchers (including linguistic 
theorists), practitioners, and policy makers might enter into a more fruitful dialogue. Hudson distinguishes between ideas and models, the former being much less controversial than the latter. He defines ideas as concepts about the nature of language, which for the most part represent "issues on which linguists can agree." For instance, all linguists agree that language skills continue to develop into adulthood, although they might disagree on why and how these skills change; they also all agree that various language skills (phonology, vocabulary, grammar, pragmatics) are separable and perhaps even uncorrelated. Models "exist at the frontier of research" as they provide alternative explanations that are controversial by nature. As pointed out by Hudson, linguists are concerned with models, and their debates about models often obscure their agreement on big ideas. Whereas linguists and developmental psychologists can argue about the specifics of varied theoretical models, the job of educational linguistics is not to seek proofs for theoretical formulations, but to generate relevant ideas for educational practice. If elucidating what teachers, students, policy makers, and other educational participants need to know about language to achieve successful outcomes is the goal, then focusing on ideas instead of models offers a wise solution. Ideas, as Hudson points out, however, are not easily inferred from theoretical linguistic writings; linguists could contribute to education by spelling out the key ideas clearly. Indeed, collaborations among theoretical and educational linguists could prove mutually advantageous as ideas relevant to educational practice are identified, and as real data from students challenge those ideas and offer evidence on which more comprehensive linguistic models might be built.

Of course, many of the "big ideas" commonly assumed to be true in the community of educational linguists need to be made more particular if they are to influence educational practice. For example, the claim that L1 instruction has a positive aspect on L2 literacy acquisition, or that advanced literacy skill is related to oral language comprehension, are generally accepted as true, but what do they actually mean for classroom practice?

Reaser and Adger (Chapter 12, this volume) review attempts to unravel specific language-related factors that explain why the mismatch between vernacular and standard languages constitutes such a challenge in school. Reaser and Adger review studies carried out by Labov and his colleagues, showing that there is a complex relationship between vernacular languages and reading. For example, some features of African American English - introduced when reading aloud standard English texts - are more likely than others to constitute reading errors.

The more specific and practice-relevant research questions get, the more they can generate other relevant questions and make significant contributions to the improvement of students' instruction and learning. An example of such a question based on the research Reaser and Adger reviewed is: "Why is it that knowledge of Standard English is so variable in the low SES population ... and what are the mechanisms by which increased knowledge of Standard American English favors learning to read?" Answers to this type 
of question have great potential to provide specifically targeted and useful advice for educational practice.

Another level at which research needs to be made relevant to practitioners is in the dissemination of findings. As Reaser and Adger (Chapter 12, this volume) foreground, communication of linguists' important insights to educational researchers requires different approaches than communication to linguists. Moreover, educational linguists should tailor their message to their various audiences - educational researchers, teachers, policy makers, and other practitioners. The dimensions of language in which each of these groups is interested, and the terminology and illustrative examples that will appeal to each, differ in important ways.

In a truly fruitful dialogue, then, linguists would articulate their big ideas, practitioners would request specific implications for practice, and linguists would track the effectiveness of those practical implications in order to hone their big ideas. In a fruitful dialogue, both participants have much to learn.

\section{The value of sharing insights across first and second language acquisition research}

Another theme encountered across chapters is the value of research on first language acquisition as a resource to educational linguists, and, in particular, as a basis for thinking about both research and practice in second/foreign language acquisition (Huhta, Chapter 33, this volume). As evidenced across chapters in this book, there are some areas in which SLA has a longer trajectory of accumulated knowledge in relation to research on L1, such as the research-practice collaborations discussed above (Pica, Chapter 37, this volume). Conversely, there are other fields in which research on L1 has deeper resources and better articulated theories, such as early literacy assessment (Huhta, Chapter 33, this volume). We celebrate the contributions of first language research to second language instruction, but note that the vast literature on first language acquisition is almost exclusively devoted to describing natural, untutored acquisition, and emerges from a commitment to constructivist views, in which the child is seen as spontaneously using input data to invent language anew. Despite recently increasing efforts to improve students' vocabulary skills via explicit instruction (Beck, McKeown, \& Kucan, 2002; Carlo et al., 2004; Biemiller \& Boote, 2006), there is still scarce research on the role of implicit or explicit instruction in first language acquisition, even though recent findings have documented enormous differences among normally developing children in language skills (e.g., Hart \& Risley, 1995), and are beginning to document the effects of language skills on content-area learning and assessment (Abedi, 2003; Butler et al., 2004).

It is also striking that, while research on first language acquisition is a source of inspiration to educational linguists, there is very little problematization within educational linguistics of crucial questions of practice related to first 
language learning. Given huge differences among children in the language skills available to them at entry to schooling, and the demonstrated consequences of those differences for later school success (Tabors, Roach \& Snow, 2001; Tabors, Snow \& Dickinson, 2001), it seems as if educational linguists need to focus on questions about how to enrich language learning opportunities in early childhood. For example: What practices should we recommend to parents and preschool teachers to ensure optimal early language development? How does exposure to different activities and activity structures (peer play, book-reading discussions, pretend play, etc.) promote the development of language, especially the foundation for academic language?

Ironically, then, educational linguistics draws deeply on research about early language acquisition, but attends only minimally to the consequences of variation in early acquired language skills for educational outcomes and has, for the most part, not exploited advances in foreign/second language teaching methods to inform instruction in vocabulary and academic language for monolinguals. It would be unwise not to take advantage of insights from wellresearched areas, such as vocabulary instruction for L2, to explore how to bring them into the mainstream of education practices. Are components identified as crucial in second language research, such as metalinguistic awareness (Ellis, Chapter 31, this volume), or "languaging" (Swain \& Suzuki, Chapter 39, this volume), also factors positively associated with more broadly defined school language and literacy skills? North (Chapter 16, this volume) even asks if a common framework developed for the teaching of foreign or second languages could be applied in primary school to the teaching of the mother tongue. As he points out, we should not lose sight of the intrinsic differences distinguishing these two learning processes and minimize the value of simple extrapolations from one field to another. Still, well-replicated findings in SLA or FL research generate hypotheses about language learning more broadly defined that deserve attention. These findings might be of particular relevance to issues that arise when classrooms serve children from multiple language backgrounds, for example those that emerge in thinking about Walter's (Chapter 10, this volume) question about what happens when the child does not speak the language of the classroom.

The global question about language acquisition that might be at the center of a systematic research agenda for educational linguistics is the following: What is the nature of the knowledge about language available to a proficient speaker at different stages of development of oral and literate skills? A corollary of this global question is the following one: How can we define and assess the more advanced language skills typically developed during middle childhood and adolescence? If we had the answers to these questions, then many other troubling issues (e.g., What new language skills are needed to process academic or disciplinary texts? What are the possibilities for transfer from a first to a second language and/or literacy system? How should teachers respond to non-standard dialects? What constitutes good classroom discussion?) would become much more tractable. 
Despite the enormous value of the basic work done on language acquisition to educational linguists, it is important to emphasize that improvements in domains such as language teaching and language assessment cannot wait for more data and better theories about either first or second language acquisition. The problems of practice are too large and too urgent, as emphasized by Jones and Saville (Chapter 35, this volume), for solutions to be postponed until all the data are collected. Indeed, one of the contributions of practitioners to research is to provide candidates of excellent practice that can then be subjected to further study and evaluation, and whose success or failure might inform theory.

\section{The challenge of instruction and assessment with more advanced learners}

Language development researchers, as noted above, have focused primarily on young children and the major advances in language skills achieved between ages 1 and 3-4 years. Their work is directly relevant to the practice of early childhood educators and has informed and improved the design of preschool and parent-involvement programs. Most educators, though, take those early accomplishments for granted, and concern themselves with later language development - development of the capacity to engage in classroom discussion, to produce extended discourse orally and in writing, to acquire sophisticated vocabulary, and deploy complex grammar. Understanding these later developmental challenges, for students operating in their first language and for those acquiring a second language, is a task with which educational linguistics could help. As Hull and Hernandez (Chapter 23, this volume) point out, adolescent literacy has lately received more attention; however, there are still numerous gaps to fill in to fully understand how to better serve older students.

As both Jones and Saville (Chapter 35, this volume), and Davies (Chapter 34, this volume) discuss, language proficiency becomes broader and more multidimensional at later ages/grades. Therefore the challenge of assessing these more sophisticated language skills also increases. Yet, in the accountabilitydriven world of education, developing assessments for these more sophisticated language skills is key, because if they are not assessed, they are unlikely to be attended to in the classroom. Furthermore, decisions about placement of second language learners in mainstream classrooms should depend on valid assessments of their ability to comprehend and produce the academic language needed for success in those classrooms; it is still the case that second language proficiency tests often focus on basic rather than academic language skills, and thus, exit students who are unprepared for the tasks they will face in mainstream classrooms (Kieffer, Lesaux, \& Snow, 2006).

Particularly when thinking about older learners, for whom language and literacy skills are the gateway to all learning, the need to integrate instruction 
and assessment becomes urgent. We agree with Huhta (Chapter 33, this volume) on the need to develop diagnostic assessments that inform teacher practice and allow for ongoing feedback between teacher and students. If, as claimed by Reaser and Adger, it is true that linguists and educational linguists are becoming interested in collaborating with educators to produce practical assessments and materials for classroom use, then the gap that currently exists in the availability of materials on language variation could be filled productively. Indeed, recent collaborations among linguists, educational linguists, and practitioners in the design and production of instructional materials and assessment have started to produce successful results (Labov and Baker, 2001, quoted by Reaser and Adger, Chapter 12, this volume).

Questions that arise, then, include the following: What are the key characteristics of academic language needed for success in the middle and secondary grades? How can these language skills best be taught? Do students benefit from instructional attention to these skills as oral language in the primary or even preschool years? Do students who have acquired academic language skills in a first language transfer useful knowledge of them to a second language, and if so, under what circumstances and for what combinations of first and second languages?

\section{Beyond language as skill: Motivation and identity in language learning}

A recurrent issue in language teaching is the motivation of learners. Motivation is a complicated issue in foreign language classes, in which the lack of a positive reason to master the language might well be compounded by all sorts of negative motivations, e.g., embarrassment, fear of making errors, loss of self-esteem, or difficulty of an honorable self-presentation during the early stages of language learning (see McKinney \& Norton, Chapter 14, this volume). Motivation can also play a role in learners' willingness to shift from a non-standard to a standard dialect (see Mesthrie, Chapter 6, this volume), or to adopt the academic language features desired for classroom discussion and for literacy.

There has been considerable research done showing the impact of motivation on second/foreign language learning and exploring the interaction between types of motivation and social setting in determining outcomes. However, the extension of these ideas to issues of identity construction within a first language has not yet happened. Within the various content areas, there is growing attention to important questions of the form: What does it mean to speak/write like a historian or a scientist? What language skills are involved, and how distinctive are they for the different content areas? The motivationrelated question that accompanies these is: How do we create classroom conditions under which students are motivated to acquire academic identities and the language skills associated with them? 
Raising issues of identity and motivation also alerts us to the degree to which research in educational linguistics has focused on some populations and language varieties to the exclusion of others. The research agenda would not be complete without an urgent call for the inclusion of those neglected populations and language varieties, as highlighted by various authors in this volume:

- Reaser and Adger (Chapter 12) for non-standard varieties beyond African American English;

- Supalla and Cripps (Chapter 13) for deaf children;

- McCarty, Skutnabb-Kangas, and Magga (Chapter 21) for endangered languages in different parts of the world;

- King and Benson (Chapter 24) for indigenous languages;

- Hull and Hernandez (Chapter 23) with a more general call to study diverse cultures, ethnicities, social classes, and gender.

As evidenced by these various calls, there is still a long list of populations awaiting researchers' attention.

\section{Conclusion}

The richness and breadth of the work presented in this volume emphasize the value of greater clarity about the definition of educational linguistics, its goals, and the fundamental questions with which it should grapple. Educational linguistics lies at the intersection of research on education and research on applied linguistics (see LoBianco, Chapter 9, this volume). While Applied Linguistics is the branch of linguistics that uses linguistic theory to address real-world problems, Educational Linguistics is the branch of Applied Linguistics that addresses real-world problems in education. By far the largest subfield within educational linguistics has always been the study of second language acquisition and second language teaching, and the rich accomplishments of that subfield are reflected in the several chapters devoted to it in this volume. However, educational linguistics is much broader in scope than just second/foreign language teaching. In fact, as argued by van Lier (Chapter 42 , this volume), it should encompass all academic learning mediated by language in one form or another.

We have argued that educational linguistics needs on the one hand to narrow its focus to pay particular attention to the most pressing real-world educational problems, and on the other hand to expand its focus beyond language teaching/learning to an understanding of how language mediates all educational encounters. Furthermore, in studying the role of language in all learning and teaching, it is extremely helpful to remember the continuum proposed by Bailey, Burkett, and Freeman (Chapter 43, this volume): from learning situations in which the language used is transparent to all concerned 
(teacher and students share a language and students control the academic language of the classroom) to situations were language use is opaque (students are still learning the basics of the classroom language, even as learning through that language is expected). Intermediate points on that continuum, where most students and teachers probably find themselves, represent differing degrees of translucency - i.e., students and teacher share a language but not necessarily all the specific linguistic features that characterize disciplinary, metacognitive, or classroom language use. Identifying the situations where lack of shared language knowledge interferes with learning, and characterizing helpful approaches to those situations, in the form of pedagogical strategies, curricular adjustments, student commitments, or reorganization of learning settings, is the common and urgent challenge for educational linguists.

\section{NOTE}

Support for the preparation of this paper came from the Institute of Educational Sciences, US Department of Education, through grants numbered R305G050201 and R305G050029, as well as from the Spencer and Hewlett Foundations through the Strategic Education Research Partnership Institute.

\section{REFERENCES}

Abedi, J. (2003). Impact of Student Language Background On Content-Based Performance: Analysis of Extant Data. CSE Report. Los Angeles, CA: National Center for Research on Evaluation.

Adger, C. T., Snow, C. E., \& Christian, D. (eds.) (2002). What Teachers Need to Know About Language. Washington, DC/McHenry, IL: Center for Applied Linguistics/ Delta Systems Co., Inc.

Bailey, A. L. \& Butler, F. A. (2004) Ethical considerations in the assessment of the language and content knowledge of U.S. school-age English learners. Language Assessment Quarterly 1(2-3), 177-193.

Beck, I., McKeown, M., \& Kucan, L. (2002). Bringing Words to Life: Robust Vocabulary Instruction. New York: Guilford Press.

Biemiller, A. \& Boote, C. (2006). An effective method for building meaning vocabulary in primary grades. Journal of Educational Psychology, 98(1), 44-62.

Burling, R. (1971). Talking to teachers about social dialects. Language Learning, 21, 221234.

Butler, F. A., Bailey, A. L., Stevens, R., Huang, B., \& Lord, C. (2004). Academic English in Fifth-Grade Mathematics, Science, and Social Studies Textbooks. CSE Report 642. Los Angeles, CA: Center for Research on Evaluation Standards and Student Testing, CRESST.

Carlo, M. S., August, D., McLaughlin, B., Snow, C. E., Dressler, C., Lippman, D. N., Lively, T. J., White, C. E. (2004). Closing the gap: Addressing the vocabulary needs of 
English-language learners in bilingual and mainstream classrooms. Reading Research Quarterly, 39(2), 188-215.

Donovan, M. S., Wigdor, S., \& Snow, C. E. (eds.) (2003). Strategic Education Research Partnership. National Research Council, Washington, DC: National Academies Press.

Fillmore, L. W. \& Snow, C. E. (2002). What teachers need to know about language. In Adger, C. T., Snow, C. E., \& Christian, D. (eds.), What Teachers Need to Know About Language. (pp. 7-53) Washington, DC/McHenry, IL: Center for Applied Linguistics/Delta Systems Co., Inc.

Hart, B. \& Risley, T. (1995). Meaningful Differences in the Everyday Experience of Young American Children. Baltimore: Brookes.

Kieffer, M., Lesaux, N., \& Snow, C. E. (2006). Promises and pitfalls: Implications of No Child Left Behind for defining, assessing, and serving English language learners. Paper prepared for Civil Rights Project Conference, Washington, DC, November.

Labov, W. \& Baker, B. (2001). Testing the effectiveness of an individualized reading program for African-American, Euro-American and Latino inner city children. Poster presented at the meeting of Interagency Educational Research Initiative Project. Washington, DC.

LeMoine, N. R. (2001). Language variation and literacy acquisition in African American students. In J. L. Harris, A. G. Kamhi, \& K. E. Pollock (eds.), Literacy in African American Communities (pp. 169-194). Mahwah, NJ: Erlbaum.

Reaser, J. \& Wolfram, W. (2005). Voices of North Carolina: Language and Life from the Atlantic to the Appalachians. Raleigh, NC: NC State University.

Snow, C. E., Griffin, P., Burns, M. S., \& NAE Subcommittee on Teaching Reading (2005). Knowledge to Support the Teaching of Reading: Preparing Teachers for a Changing World. San Francisco, CA: Jossey-Bass.

Tabors, P. O., Roach, K. A., \& Snow, C. E. (2001). Home language and literacy environment final results. In D. K. Dickinson \& P. O. Tabors (eds.), (2001). Beginning Literacy with Language (pp .111-138). Baltimore: Paul H. Brookes Publishing Co.

Tabors, P. O., Snow, C. E., \& Dickinson, D. K. (2001). Homes and schools together: Supporting language and literacy development. In D. K. Dickinson \& P. O. Tabors (eds.), Beginning Literacy with Language (pp. 313-334). Baltimore: Paul H. Brookes Publishing Co.

Valdés, G., Bunch, G., Snow, C., Lee, C., \& Matos, L. (2005). Enhancing the development of students' language(s). In L. Darling-Hammond \& J. Bransford (eds.), Preparing Teachers for a Changing World: What Teachers should Learn and Be Able to Do. San Francisco, CA: Jossey-Bass.

Wolfram, W., Schilling-Estes, N., \& Hazen, K. (1997). Dialects and the Ocracoke Brogue. Raleigh, NC: NC State University. 